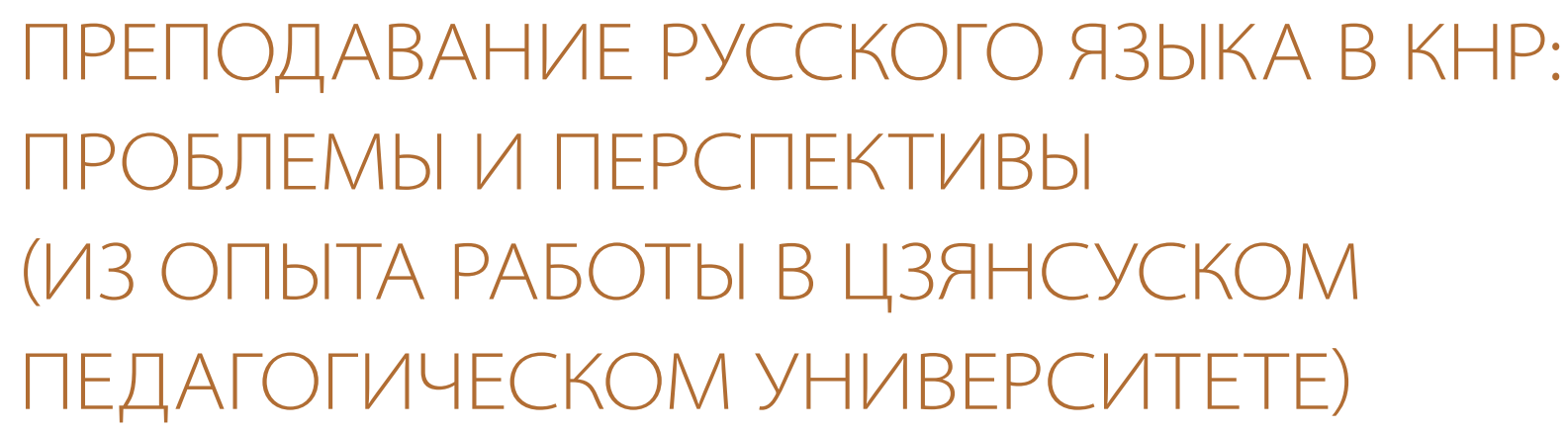

\title{
THE RUSSIAN LANGUAGE TEACHING IN CHINA: PROBLEMS AND PROSPECTS (FROM THE EXPERIENCE AT JIANGSU NORMAL UNIVERSITY)
}

\section{Цыренова Мария Ивановна}

Доцент кафедры контрастивной лингвистики, Московский педагогический государственный университет, кандидат педагогических наук; Китайско-Российский Институт, Цзянсуский педагогический университет (г. Сюйчжоу, Китай) E-mail: mariya.cyrenova@gmail.com

Аннотация. В статье рассматривается сложившаяся за последние годы ситуация с преподаванием русского языка как иностранного в Китайской народной республике, выявляются проблемы, перспективы и дальнейшие тенденции развития, обосновывается актуальность заявленной темы. Данные, представленные в тексте, основаны на анализе теоретических и практических исследований как российских, так и китайских русистов, сделанных за последние 5 лет в условиях языковой и неязыковой среды, а также на беседе, проведенной среди преподавателей, имевших

\section{Tsyrenova Maria I.}

Assistant Professor at the Department of contrastive linguistics, Moscow Pedagogical State University, PhD in Education; ChineseRussian Institute, Jiangsu Normal University (Xuzhou, China)

E-mail: mariya.cyrenova@gmail.com

Abstract. The article deals with the recent situation in which teaching of the Russian language is in China. It identifies problems, prospects and further trends of development, substantiates the relevance of the topic. The data presented in the text is based on the analysis of theoretical and practical studies carried out by both Russian and Chinese teachers of Russian, conducted for over the latest 5 years in the conditions of the linguistic and non-linguistic environment as well as in a conversation held among teachers who had working experience in Chinese universities, 
опыт работы в китайских вузах, собственных наблюдениях и личном опыте преподавания в Цзянсуском педагогическом университете (г. Сюйчжоу, Китай). Полученные выводы могут представлять интерес как для преподавателей русского языка, непосредственно работающих либо планирующих поехать работать в Китай, так и для всех русистов.

Ключевые слова: русский язык как иностранный в Китае, преподавание русского языка как иностранного нефилологам, опыт работы в китайском вузе, китайские студенты, медиатехнологии.

\begin{abstract}
and the author's own observations and personal experience of teaching in Jiangsu Normal University. The conclusions may be interesting both for teachers of the Russian language working or intending to work in China, as well as for all teachers of Russian.
\end{abstract}

Keywords: Russian as a foreign language in China, teaching Russian to nonphilologists, teaching experience in a Chinese university, Chinese students, media-technologies.

В статье рассмотрена сложившаяся ситуация с преподаванием русского языка как иностранного (далее: РКИ) в КНР, так как за последние несколько лет между нашими странами укрепились и получили новый виток связи во всех отраслях: экономических, политических, культурных. Данные основаны на результатах теоретических и практических исследований, проведенных русистами в Китае [1-6], собственных наблюдений, преподавательской деятельности в китайском вузе, а также на итогах беседы среди коллег, работавших длительное время в китайских университетах.

Преподавание русского языка в Китае самым тесным образом, в первую очередь, связано с политическими взаимоотношениями между Китайской Народной Республикой и Российской Федерацией, с ситуацией на рынке труда и спросе на специалистов в данной области.

Так, в истории преподавания РКИ в КНР можно выделить несколько этапов. Первый этап проходил в 1950-е гг., когда в стране наблюдался бум обучения русскому языку, который стал первым иностранным языком КНР. Данный факт стал следствием того, что в послевоенный период СССР тесно сотрудничал с жителями Поднебесной во всех областях народного хозяйства. В 1960-е и 1970-е гг. по мере того, как ухудшались отношения между Китаем и СССР, резко сократилось и количество желающих изучать русский язык.

Многие русисты вынуждены были сменить квалификацию, некоторые из них стали преподавать английский язык, который занял место русского, приобретя статус основного иностранного языка. Такую тенденцию, к сожалению, можно наблюдать и по сегодняшний день. Причем преподавателей - специалистов по английскому языку в стране не хватает до такой степени, что на должность учителя в языковые школы зачастую нанимают любого носителя языка без соответствующего образования и опыта работы.

С середины 1980-х гг. преподавание РКИ в КНР начало постепенно восстанавливаться. В 1981 г. была создана Китайская ассоциация преподавателей русского языка и литературы (КАПРЯЛ) как ответвление Международной ассоциации (МАПРЯЛ). В этом же году 
стали выходить журналы «Русский язык в Китае», «Русский язык в средней школе» и «Русская литература». Укрепление позиции русского языка в Китае связано с тем, что в данный период увеличилось сотрудничество между нашими странами, начался культурный обмен студентами и преподавателями, оживилась приграничная торговля. Как следствие этих причин стало появление во многих вузах страны целых отделений русского языка. Особенно активно этот процесс шел на севере Китая, где традиционно почти в каждом университете оставались и остаются студенты, изучающие русский язык как основную специальность.

В настоящее время преподавание русского языка в Китае заняло свое место. По словам директора Центра изучения русского языка Пекинского университета иностранных языков Ли Иннань, русский язык сейчас находится на втором месте, опередив французский и немецкий языки [7]. Как основную специальность его изучают в 140 китайских вузах. Общее число студентов, обучающихся по данной специальности, составляет «около 30000 человек, в числе которых более 4000 учатся в магистратуре и около 600 человек в докторантуре» [8, с. 3].

Большинство вузов, в которых преподается русский язык, как мы указали выше, располагается на севере страны, особенно в ее северо-восточной части, так как именно там проходит общая граница между Россией и Китаем. Ведущий вуз по этому направлению (изучению и преподаванию РКИ) находится в провинции Хэйлунцзян, где имеется не только институт русского языка, но и центр его изучения.

Тем не менее следует отметить тот факт, что, к сожалению, в последнее время в вузах Китая сократилось количество учебных часов при обучении иностранным языкам. В создавшихся условиях и на современном этапе развития методики преподавания РКИ, по мнению китайских русистов, наступил момент, когда следует «разрушить традиционные шаблоны в системе образования и изменить старую форму обучения» [9, с. 71], нужны новые адекватные методы для достижения наилучшего эффекта [10, с. 102]. Необходимо организовать внеаудиторную деятельность для стимулирования мотивации в изучении русского языка, также перед преподавателями встал вопрос большего использования и вовлечения в учебный процесс информационных технологий, в том числе различных медиатехнологий.

В настоящее время во многих китайских вузах создаются аудитории, оснащенные последними новинками аудио-, видео-, компьютерной техники. В таких помещениях, на наш взгляд, можно проводить занятия по всем видам речевой деятельности: аудированию, говорению, чтению, письму. Вместе с тем обычные аудитории зачастую также оснащены компьютерами с доступом в Интернет, проектными экранами, микрофонами. Преподаватели могут весь подготовленный дома материал представить на данных экранах с помощью USB-флеш-накопителя, либо CD/DVD. Таким образом, компьютер и информационные технологии в Китае уже прочно вошли в практику преподавания и стали незаменимыми помощниками в обучении различных предметов, в частности РКИ.

Такие виды речевой деятельности, как аудирование, говорение, необходимо отрабатывать в подобных мультимедийных аудиториях, где можно одновременно смотреть, слушать, говорить на изучаемом языке. В китайском вузе в одной группе может обучаться до 
40 и более студентов одновременно. Данное количество превышает количество учащихся в одной группе в языковой среде в среднем в 4 раза.

Поэтому на уроках по говорению у каждого конкретного учащегося в неязыковой среде меньше возможностей развить навыки говорения на изучаемом языке, так как элементарно не хватает времени - ни внеаудиторного, ни тем более аудиторного. Вследствие этого преподаватели в ходе подготовки к занятию подбирают нужные материалы и вопросы, по которым студенты должны сделать сообщение или на которые должны ответить, записывают на USB-флеш-накопитель и затем на занятии транслируют их на общий большой экран.

В свою очередь, студенты могут записать свое выступление как монологическое высказывание, так и диалог или ответы на диктофон. Преподаватели прослушивают и проверяют ответы уже после занятия. Таким образом экономится аудиторное время, обеспечивается возможность для каждого студента развить навыки говорения как в продуктивной форме, так и в репродуктивной. Данная методика широко применяется на уроках по практическому курсу русской разговорной речи, используется на государственных экзаменах. Стоит отметить, что данную практику записывания диалога или подготовленного монолога возможно применять и в условиях отсутствия вышеназванных мультимедийных аудиторий. На помощь могут прийти имеющиеся у всех наших студентов телефоны с записывающим устройством.

Как мы выяснили из результатов беседы с преподавателями РКИ, работающими в условиях китайских вузов, в некоторых из них наших коллег просят составлять так называемые компьютерные обучающие программы, суть которых заключается в том, что преподаватель готовит на своем компьютере и затем приносит на занятия дополнительный материал по теме либо по тексту пройденного урока, а также вводит в этот материал новую лексику, касающуюся пройденной темы. В качестве иллюстраций часто используются картины русских художников, музыкальные произведения, что вызывает живой интерес у студентов.

В результате такой работы над каждым текстом учебника получается полноценное занятие с применением современных технологий. Такая работа, по нашему мнению, является очень продуктивной с точки зрения методики обучения РКИ, и, собрав несколько таких электронных уроков, можно создать, к примеру, свой собственный интерактивный курс по изучению русского искусства XIX в.

К достоинствам обучения русскому языку при помощи медиатехнологий, во-первых, можно отнести тот факт, что появляется возможность давать одновременно основную информацию и фоновые знания из области культуры.

Во-вторых, можно сэкономить аудиторное время занятий и при этом дать студентам больше возможностей говорить на изучаемом языке, приобрести больше знаний за отведенную единицу времени.

В-третьих, повышается статус студента. Если раныше преподаватели играли главенствующую роль в учебном процессе, то в настоящее время преподаватели и студенты являются партнерами, что является одним из основополагающих принципов личностноориентированного подхода в методике преподавания РКИ. Преподаватель просто направляет студентов, которые сами приобретают свои знания. 
Стоит отметить, что данный аспект приобретает особое значение именно в китайской аудитории, так как именно в ней некоторые студенты - недавние школьники - настолько запуганы и боятся проявить инициативу в силу культурных и учебных особенностей воспитавшей их страны, что необходимо уже на начальном этапе показать им, что вы как преподаватель и они как студенты равны и что вы с ними являетесь, в первую очередь, партнерами. Сами наши китайские коллеги пишут о том, что учитель «должен стать не только наставником, но и другом студента» [9, с. 71].

Наблюдения, сделанные непосредственно автором статьи, касаются работы в Цзянсуском педагогическом университете, находящемся в провинции Цзянсу, в городе Сюйчжоу с численностью населения около 8 млн человек. В составе университета имеется филологический факультет, где студенты изучают русский язык как специальность, но таких желающих набирается довольно малое количество.

Стоит отметить, что на данном факультете в контракте у преподавателей прописаны такие коммуникативно-направленные занятия, как уроки русской кухни [11, с. 25], что предполагает у китайских русистов довольно близкое знакомство с русской культурой.

В основном же российские преподаватели ведут занятия в Совместном инженерном институте, который был создан относительно недавно - в 2016 г. в сотрудничестве с Санкт-Петербургским политехническим университетом Петра Великого. Для китайцев, изучающих здесь русский язык, он является второй специальностью. Основными же направлениями института являются конструкторско-технологическое обеспечение машиностроительных производств, промышленный дизайн, инфокоммуникационные технологии, системы связи, электроника и наноэлектроника. Два года студенты обучаются в стенах Цзянсуского педагогического университета, и затем в течение двух лет наиболее успешные учащиеся познают азы технических специальностей на русском языке в Санкт-Петербурге. По окончании бакалавритата они получают два диплома: китайский и российский. После этого они могут продолжить свое обучение в магистратуре либо начать работать.

Нашим студентам русский язык необходим в основном для дальнейшего обучения в России, а также для возможного трудоустройства в российско-китайской компании, что является очень престижным достижением. Данная форма подготовки двойных специалистов становится в последние годы на территории Китая довольно распространенной. Так, «в Харбинском политехническом университете специальность "русский язык" сочетается с космонавтикой, в Северо-восточном сельскохозяйственном университете - с агрономией, в Северо-восточном лесотехническом университете - с лесным делом» [12, с. 12].

Одним из первых наших открытий в начале работы в китайском вузе стал тот факт, что в Китае принята система раздельного освоения всех четырех видов речевой деятельности. Как правило, занятия по грамматике, чтению и письму ведутся китайскими преподавателями, а русскоговорящим специалистам (не только из России, но и из других стран СНГ) отдаются в ведение занятия по аудированию и говорению - так называемый аудиовизуальный курс.

Причем данная система распространяется, как показали наши опросы, на все иностранные языки. К сожалению, нами также был отмечен тот факт, что преподавателями 
по РКИ становились не всегда специалисты-филологи, но и специалисты из других областей, без соответствующего опыта работы. Справедливости ради следует отметить, что со временем профильных специалистов стало болыше. В данном вузе каждый семестр у большинства групп менялся преподаватель. С одной стороны, данная смена была положительным фактором, так как студенты таким образом получали возможность в аудировании разных голосов, разных тембров и темпов речи носителей языка. С другой стороны, на наш взгляд, преподаватель не успевал отследить у студентов тот прогресс, который у них происходил от самого первого занятия и до последнего.

Во время своей работы в вузе мы столкнулись с преподавателями, которые представлялись учащимся своими именами в краткой форме, считая, что таким образом облегчают им понимание их имени и в дальнейшем использование его в речи. Конечно, мы согласны с тем, что овладение любым предметом необходимо по возможности облегчать для того, чтобы студенту было более комфортно на занятиях и он мог за определенную единицу времени достигнуть наилучших результатов.

Но, с другой стороны, одной из наших первостепенных задач, как нам видится, остается погружение иностранных студентов в иную для них языковую среду, языковую картину мира, тем более в условиях другой страны, и вот с этой точки зрения становится понятно, что в русской картине мира не обойтись без называния человека по имени и отчеству, ведь, в первую очередь, обучая наших студентов, мы обучаем их РКИ в учебной сфере общения, а также официально-деловой.

В качестве главного учебного пособия в университете был выбран учебник «Дорога в Россию», по которому занимались как наши китайские коллеги, так и российские, что зачастую приводило к повторной подаче материала [13]. Данный факт мы бы отнесли к положительным моментам, так как шло повторение пройденных грамматических правил, лексики и т. д. Также дополнительно российские специалисты использовали в своей работе учебное пособие, разработанное авторским коллективом Пекинского университета, - Базовый аудиовизуальный курс русского языка в трех частях. Данный курс вызвал в основном положительные отзывы со стороны преподавателей из России, так как достаточно успешно развивал и закреплял навыки аудирования и говорения [14].

Кроме того, вторым открытием после нашей работы в Китае стал тот факт, что в КНР уже на протяжении последних десяти лет проводится собственное тестирование по РКИ. Местными специалистами были разработаны восемь уровней владения русским языком. Как мы выяснили, в первые четыре не входит такой важный, на наш взгляд, субтест, как говорение, но в то же время выделяется перевод как отдельный вид заданий. Тестирование проводится, с нашей точки зрения, в более жестких условиях, чем в России, всего один раз в год, одновременно по всей стране вне зависимости от часового пояса.

В китайской системе тестирования были выделены объективные и субъективные субтесты. К субъективным отнесли говорение, письмо. Тем не менее все субтесты проводятся без участия тесторов, в лингафонных кабинетах. Во время проведения субтеста говорения ответы записываются на магнитофон. И это понятно, так как зачастую на тестирование в один центр может прийти около тысячи кандидатов, и тесторы просто физически не успевали бы за один день принять экзамен у всех желающих. 
Тестирование проводится не по общепринятым в системе ТРКИ уровням (A1, A2, B1, B2, C1, C2), а только по четвертому, шестому и восьмому. Тесты делятся в зависимости от того, кому предназначены: филологам (четвертый и восьмой уровни) либо нефилологам (четвертый и шестой уровни). Студенты Китайско-российского института Цзянсуского педагогического университета в конце первого курса сдают тест четвертого уровня для нефилологов, а в конце второго - тест шестого уровня. По мнению Линся Мэн, «подобные тестирования не полностью показывают уровень студентов, которые хоть и имеют широкий словарный запас, но не могут употреблять конкретные слова в разговорной речи» [15, с. 71]. Тем не менее, с точки зрения Фэн Шисюань, в Китае в настоящее время уделяется большое внимание формированию именно коммуникативных навыков [9].

К сожалению, мы не смогли провести наблюдения совместной работы китайских русистов и российских специалистов по РКИ в том институте, в котором нам удалось поработать, так как наши коллеги из Китая избегали общения. И мы так и не смогли прийти к выводу, по какой причине это произошло. Хотя в то же время в Цзянсуском педагогическом университете ведется активная деятельность по привлечению новых партнеров - вузов из России, Украины, выделен отдельный китайско-российский институт со своим учебным корпусом, Центр русского языка, в котором полным ходом идет работа. Так, китайские преподаватели постоянно проходят курсы повышения квалификации, Санкт-Петербургский политехнический университет Петра Великого разработал учебное пособие по научному стилю речи (первый сертификационный уровень), по которому студенты начинают обучаться на втором курсе [16].

В качестве заключения нашего краткого обзора современной ситуации в преподавании РКИ в КНР и изложения опыта работы в китайском вузе мы хотели бы дать некоторые рекомендации будущим преподавателям русского языка в Китае.

Во-первых, необходимо установить более тесные контакты и взаимоотношения с нашими китайскими коллегами, создать методическое объединение, в которое должны войти как российские специалисты, так и китайские.

Во-вторых, совместно с китайскими русистами разрабатывать учебные пособия конкретно для своего университета.

B-третьих, нужно постепенно убеждать некоторых из наших коллег из Китая, что на уроках по РКИ необходимо уходить от грамматико-переводного метода и давать комплексное развитие всех четырех видов речевой деятельности. Хотя сами наши китайские коллеги отмечают, что «изменение представлений и привычек педагогов и обучающихся в области учения и обучения русскому языку - дело непростое» [10, с. 103].

\section{Список литературы}

1. Антонова Ю. А. О некоторых тонкостях преподавания РКИ китайским студентам // Педагогическое образование в России. 2016. № 12. С. 13-16.

2. Дай Хуэй. О преподавании русского языка в Китае: проблемы и перспективы // Русский язык за рубежом. Специальный выпуск. 2017. C. 8-10. URL: http:// pushkin.institute/science/russkiy_yazyk_za_rubezhom/RYAZR_Kitay.pdf (дата обращения: 17.10.2019). 
3. Иванова И. С. Изучение русского языка в Китае (из опыта работы в Хайнаньском университете) // Научно-методический электронный журнал «Концепт». 2014. № 13. C. 36-40. URL: http://e-koncept.ru/2014/14655.html (дата обращения: 21.10.2019).

4. Леханова К. Н. Особенности обучения китайских студентов русскому языку как иностранному (из опыта работы в институте Бода Цзилиньского педагогического университета, КНР) // Вестн. Сев.-Вост. федерального ун-та им. М. К. Аммосова. Сер.: Педагогика. Психология. Философия. 2018. № 4. С. 38-46.

5. Лю Сумэй. Обучение русскому языку в вузах Китая: состояние и перспективы // Русский язык за рубежом. 2014. № 4. С. 120-123.

6. Цзоу Д., Березовская Я. Л. Изучение русского языка в Китае // Язык. Культура. Коммуникации. 2015. № 1. URL: https://journals.susu.ru/lcc/article/view/128/323 (дата обращения: 13.10.2019).

7. Ли Иннань. В Китае русский язык - серьезный бренд // Русский мир: информационный портал фонда «Русский мир». URL: https://russkiymir.ru/ publications/87968/ (дата обращения: 21.10.2019).

8. Лю Лиминь. Русский язык в Китае // Газета «Жэньминь жибао» он-лайн. URL: http://russian.people.com.cn/31521/2920106.html (дата обращения: 21.10.2019).

9. Фэн Шисюань. Изучение русского языка китайскими студентами: проблемы, возможности, перспективы // Вестн. Российского ун-та дружбы народов. Сер.: Русский и иностранные языки и методика их преподавания. 2015. № 2. С. 70-74.

10. Цзоу Чжэнъчжу, Сюй Хун. Изучение русского языка в сфере межкультурной коммуникации // Вестник ЮУрГУ. Сер.: «Образование. Педагогические науки». 2018. T. 10, № 1. C. 102-106. DOI: https://doi.org/10.14529/ped180112.

11. Мартынова М. А., Ковалеъа Н. А., Юн Л. Г. Организационно-методические особенности работы с китайскими учащимися при обучении в условиях отсутствия языковой среды // Русский язык за рубежом. Специальный выпуск. 2017. C. 15-26. URL: http://pushkin.institute/science/russkiy_yazyk_za_rubezhom/RYAZR_Kitay. pdf (дата обращения: 17.10.2019).

12. Ли Хэнжэнь. Инновация в подготовке специалистов по русскому языку в нефтяных вузах (на примере Северо-Восточного нефтяного университета) // Русский язык за рубежом. Специальный выпуск. 2017. C. 11-14. URL: http://pushkin. institute/science/russkiy_yazyk_za_rubezhom/RYAZR_Kitay.pdf (дата обращения: 17.10.2019).

13. Дорога в Россию: учебник русского языка (элементарный уровень) / В. Е. Антонова, М. М. Нахабина, М. В. Сафронова, А. А. Толстых. СПб.: Златоуст, 2012. $344 \mathrm{c}$.

14. Базовый аудиовизуальный курс / И. В. Таюрская. Beijing: Peking University Press, 2010. 117 c.

15. Линся Мэн. Обучение русскому как иностранному в вузах Китая: проблемы и пути их решения (из опыта преподавателей Муданьцзянского педагогического университета) // Вестн. Томского гос. пед. ун-та. 2016. № 7. С. 70-75. 
16. Баранова И. И., Гладких И. А., Стародуб В. В. Технический русский язык (первый сертификационный уровень). СПб.: Политех-пресс, 2019. 131 с.

\section{References}

1. Antonova $\mathrm{Yu}$. A. O nekotorykh tonkostyakh prepodavaniya RKI kitayskim studentam. Pedagogicheskoe obrazovanie v Rossii. 2016, No. 12, pp. 13-16.

2. Dai Hui. O prepodavanii russkogo yazyka v Kitae: problemy i perspektivy. Russkiy yazyk za rubezhom. Spetsialnyy vypusk. 2017, pp. 8-10. Available at: http://pushkin.institute/science/russkiy_yazyk_za_rubezhom/RYAZR_Kitay.pdf (accessed: 17.10.2019).

3. Ivanova I. S. Izuchenie russkogo yazyka v Kitae (iz opyta raboty v Khaynanskom universitete). Nauchno-metodicheskiy elektronnyy zhurnal "Kontsept". 2014, No. 13, pp. 36-40. Available at: http://e-koncept.ru/2014/14655.html (accessed: 21.10.2019).

4. Lekhanova K. N. Osobennosti obucheniya kitayskikh studentov russkomu yazyku kak inostrannomu (iz opyta raboty v institute Boda Tszilinskogo pedagogicheskogo universiteta, KNR). Vestn. Sev.-Vost. federalnogo un-ta im. M. K. Ammosova. Ser.: Pedagogika. Psikhologiya. Filosofiya. 2018, No. 4, pp. 38-46.

5. Liu Sumei. Obuchenie russkomu yazyku v vuzakh Kitaya: sostoyanie i perspektivy. Russkiy yazyk za rubezhom. 2014, No. 4, pp. 120-123.

6. Zou D., Berezovskaya Ya. L. Izuchenie russkogo yazyka v Kitae. Yazyk. Kultura. Kommunikatsii. 2015, No. 1. Available at: https://journals.susu.ru/lcc/article/view/128/323 (accessed: 13.10.2019).

7. Li Innan. V Kitae russkiy yazyk - seryeznyy brend. Available at: http://russian.people. com.cn/31517/6382726.html (accessed: 21.10.2019).

8. Liu Limin. Russkiy yazyk v Kitae. Available at: http://russian.people.com. cn/31521/2920106.html (accessed: 21.10.2019).

9. Feng Shixuan. Izuchenie russkogo yazyka kitayskimi studentami: problemy, vozmozhnosti, perspektivy. Vestn. Rossiyskogo un-ta druzhby narodov. Ser.: Russkiy i inostrannye yazyki i metodika ikh prepodavaniya. 2015, No. 2, pp. 70-74.

10. Zou Zhenzhu, Xu Hong. Izuchenie russkogo yazyka v sfere mezhkulturnoy kommunikatsii. Vestnik YuUrGU. Ser.: „Obrazovanie. Pedagogicheskie nauki“. 2018, Vol. 10, No. 1, pp. 102-106. DOI: https://doi.org/10.14529/ped180112.

11. Martynova M. A., Kovaleva N. A., Yun L. G. Organizatsionno-metodicheskie osobennosti raboty s kitayskimi uchashchimisya pri obuchenii v usloviyakh otsutstviya yazykovoy sredy. Russkiy yazyk za rubezhom. Spetsialnyy vypusk. 2017, pp. 15-26. Available at: http://pushkin.institute/science/russkiy_yazyk_za_rubezhom/RYAZR_Kitay.pdf (accessed: 17.10.2019).

12. Li Hengren. Innovatsiya v podgotovke spetsialistov po russkomu yazyku v neftyanykh vuzakh (na primere Severo-Vostochnogo neftyanogo universiteta) // Russkiy yazyk za rubezhom. Spetsialnyy vypusk. 2017, pp. 11-14. Available at: http:// pushkin.institute/science/russkiy_yazyk_za_rubezhom/RYAZR_Kitay.pdf (accessed: 17.10.2019). 
13. Antonova V. E., Nakhabina M. M., Safronova M. V., Tolstykh A. A. Doroga v Rossiyu: uchebnik russkogo yazyka (elementarnyy uroven). St. Petersburg: Zlatoust, 2012. 344 p.

14. Tayurskaya I. V. Bazovyy audiovizualnyy kurs. Beijing: Peking University Press, 2010. $117 \mathrm{p}$.

15. Linsya Men. Obuchenie russkomu kak inostrannomu v vuzakh Kitaya: problemy i puti ikh resheniya (iz opyta prepodavateley Mudantszyanskogo pedagogicheskogo universiteta). Vestn. Tomskogo gos. ped. un-ta. 2016, No. 7, pp. 70-75.

16. Baranova I. I., Gladkikh I. A., Starodub V. V. Tekhnicheskiy russkiy yazyk (pervyy sertifikatsionnyy uroven). St. Petersburg: Politekh-press, 2019. 131 p.

\section{Интернет-журнал \\ «Проблемы современного образования» \\ 2020, № 3}

Статья поступила В редакцию 22.10.2019

The article was received on 22.10.2019 